Check for updates

Cite this: RSC Adv., 2022, 12, 692

Received 1st November 2021

Accepted 20th December 2021

DOI: $10.1039 / \mathrm{d} 1 \mathrm{ra0} 08015 f$

rsc.li/rsc-advances

\section{Benzyl thioether formation merging copper catalysis $\dagger$}

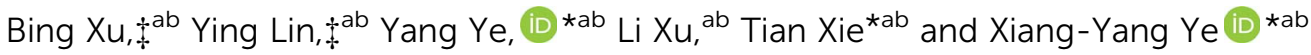

A novel copper-catalyzed thioetherification reaction has been developed to afford benzyl thioethers in moderate to excellent yields. Under the mild and easy-to-operate conditions, a variety of thioethers are efficiently prepared from readily available benzyl alcohols (primary, secondary, and tertiary) and thiols in the presence of $\mathrm{Cu}(\mathrm{OTf})_{2}$ as the Lewis acid catalysis. This $\mathrm{C}-\mathrm{S}$ bond formation protocol furnishes exceptional chemoselectivity, and the preliminary mechanism studies show that the reaction should proceed through a Lewis-acid-mediated $\mathrm{S}_{\mathrm{N}} 1$-type nucleophilic attack of the carbocations formed in situ.

\section{Introduction}

Sulfur compounds often show different biological activities and have important application value in the pharmaceutical industry. ${ }^{1}$ Thioethers are a type of sulfur-containing compound with diverse physiological activities ${ }^{2}$ and unique physicochemical properties. ${ }^{3}$ As an important structural unit, thioethers widely exist in natural products, ${ }^{4}$ drugs $^{2,5}$ and organic functional materials. ${ }^{3 a, 6}$ For example (Scheme 1A), montelukast ${ }^{7}$ is a selective leukotriene receptor antagonist approved for oral treatment of asthma and allergic rhinitis. Ufiprazole ${ }^{8}$ can be used to treat acid related diseases such as peptic ulcer and gastroesophageal reflux disease. Diltiazem ${ }^{9}$ is a safe and effective drug for the treatment of supraventricular arrhythmia, angina pectoris and hypertension in the elderly. Ranitidine ${ }^{\mathbf{1 0}}$ is a digestive system drug used to relieve stomachache, heartburn and acid reflux caused by excessive gastric acid. In addition, studies have shown that thioethers can also be used as biopheromones for animal communication. ${ }^{11}$

In view of the significant and broad potential applications of thioethers, chemists have developed a series of methods to construct thioethers based on the alkyl alcohol substrates, ${ }^{12,18-20}$ which constitute an important part of our chemical feedstocks. ${ }^{13-15}$ A variety of sulfide compounds were synthesized through these methods, ${ }^{16}$ but the disadvantages of the traditional methods are usually accompanied that can not be ignored, ${ }^{17}$ such as largely they require harsh or strong acidic

${ }^{a}$ School of Pharmacy, Hangzhou Normal University, Hangzhou, Zhejiang 311121, PR China. E-mail: yangye@hznu.edu.cn

${ }^{b}$ Key Laboratory of Elemene Class Anti-Cancer Chinese Medicines, Engineering Laboratory of Development and Application of Traditional Chinese Medicines, Collaborative Innovation Center of Traditional Chinese Medicines of Zhejiang Province, Hangzhou Normal University, Hangzhou, Zhejiang 311121, PR China

$\dagger$ Electronic supplementary information (ESI) available. See DOI: 10.1039/d1ra08015f

\$ These authors contributed equally. conditions to stimulate the reaction of alkyl alcohols with thioalcohols or thiophenols, ${ }^{18}$ and the reaction have poor step economy and atomic economy. These shortcomings limit the applications of these reactions to a certain extent. Recently, Lewis acid and transition metal catalyzed construction of thioethers using activated or non-activated alkyl alcohols have been greatly developed, ${ }^{19,20}$ which often have the following characteristics compared with the traditional synthesis methods: (1) higher atomic economy; (2) mild and easy-to-operate manners; (3) shorter synthesis steps and less-waste generation. Therefore, some examples have been discretely reported for the thiolation of benzyl alcohols under Lewis acid catalyzed reaction conditions, such as Zn-, Zr-, In-, Fe-complexes, etc. (Scheme 1B) ${ }^{20}$

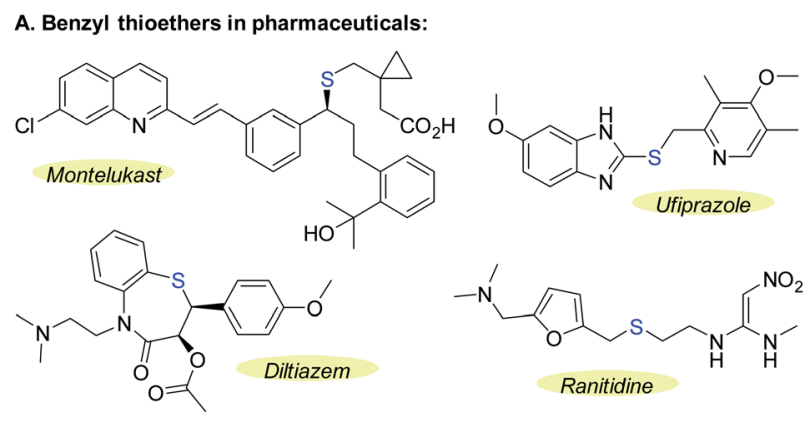

B. Thioetherification of alkyl alcohols with thiols:

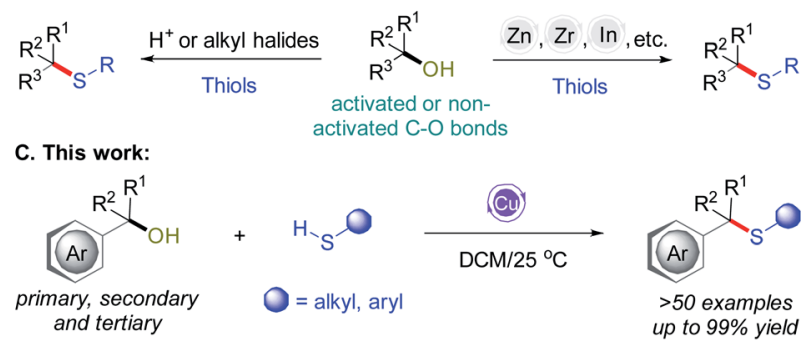

Scheme 1 Benzyl thioethers and thioetherification reactions. 
However, there is still a great demand for the preparation of benzyl thioethers from readily accessible alcohol precursors under more available and mild catalytic conditions.

From this initiative, we explored a process for thioetherification of benzyl alcohols with thiols catalyzed by a $\mathrm{Cu}-$ complex with intriguing results (Scheme 1C). More specifically, most reactions were highly chemoselective with near equimolar quantities of the products, and occurred at mild temperature. Multiple functional groups were well tolerated. The preliminary mechanistic studies were also discussed.

\section{Results and discussion}

We initiated our investigation by exploring the thioetherification of 2-phenylpropan-2-ol 1 with 4-fluorobenzenethiol 2 as the model substrates (Table 1). ${ }^{21}$ An extensive screening of the reaction parameters revealed that the use of $\mathrm{Cu}(\mathrm{OTf})_{2}$ (3 $\mathrm{mol} \%$ ) in DCM (dichloromethane) at an air atmosphere of $25{ }^{\circ} \mathrm{C}$ delivered benzyl sulfide product 3 in $96 \%$ yield (entry 1 ). Under the selected conditions, Lewis acids appeared to have great influence on this $\mathrm{C}-\mathrm{S}$ bond transformation. After the screening for $\mathrm{Cu}$ sources, $\mathrm{Cu}(\mathrm{OTf})_{2}$ was the best copper catalyst for this thioetherification reaction (Table $\mathrm{S} 5 \dagger){ }^{21}$ Without $\mathrm{Cu}(\mathrm{OTf})_{2}$, the reaction could not afford 3 (entry 2). Next, the amount of $\mathrm{Cu}(\mathrm{OTf})_{2}$ was briefly screened in Table 1 , the use of $1 \mathrm{~mol} \% \mathrm{Cu}(\mathrm{OTf})_{2}$ generated 3 in a low yield (entry 3 ) and when added more $\mathrm{Cu}(\mathrm{OTf})_{2}$ could produce 3 in reasonable high yields (entries 4 and 5), whereas replacing $\mathrm{Cu}(\mathrm{OTf})_{2}$ with other Lewis acids did not result in better outcomes (entries 6-8). Replacement of DCM by DCE (1,2-dichloroethane) led to an inferior yield, that was shown to be an unsuitable solvent (entry 9).

Table 1 Optimization for the formation of 3

\begin{tabular}{|c|c|c|c|}
\hline & $\mathrm{Me}_{\mathrm{OH}}^{\mathrm{Me}}$ & $\begin{array}{l}2(0.30 \mathrm{mmol}) \\
\begin{array}{l}\text { DCM }(1 \mathrm{~mL}) \\
25^{\circ} \mathrm{C}, \text { air, } 12 \mathrm{~h}\end{array}\end{array}$ & \\
\hline Entry & \multicolumn{2}{|c|}{ Variation from standard conditions $^{a}$} & Yield $^{b}[\%]$ \\
\hline 1 & \multicolumn{2}{|c|}{ None } & 96 \\
\hline 2 & \multicolumn{2}{|c|}{$\mathrm{W} / \mathrm{o} \mathrm{Cu}(\mathrm{OTf})_{2}$} & No reaction \\
\hline 3 & \multicolumn{2}{|c|}{$\mathrm{Cu}(\mathrm{OTf})_{2}(1 \mathrm{~mol} \%)$} & 65 \\
\hline 4 & \multicolumn{2}{|c|}{$\mathrm{Cu}(\mathrm{OTf})_{2}(5 \mathrm{~mol} \%)$} & 99 \\
\hline 5 & \multicolumn{2}{|c|}{$\mathrm{Cu}(\mathrm{OTf})_{2}(8 \mathrm{~mol} \%)$} & 99 \\
\hline 6 & \multicolumn{2}{|c|}{$\mathrm{Ni}(\mathrm{OTf})_{2}$ instead of $\mathrm{Cu}(\mathrm{OTf})_{2}$} & 61 \\
\hline 7 & \multicolumn{2}{|c|}{$\mathrm{Zn}(\mathrm{OTf})_{2}$ instead of $\mathrm{Cu}(\mathrm{OTf})_{2}$} & 15 \\
\hline 8 & \multicolumn{2}{|c|}{$\mathrm{Sc}(\mathrm{OTf})_{2}$ instead of $\mathrm{Cu}(\mathrm{OTf})_{2}$} & 44 \\
\hline 9 & \multicolumn{2}{|c|}{ DCE instead of DCM } & 91 \\
\hline 10 & \multicolumn{2}{|c|}{$0{ }^{\circ} \mathrm{C}$} & 34 \\
\hline 11 & \multicolumn{2}{|c|}{$50{ }^{\circ} \mathrm{C}$} & 98 \\
\hline 12 & \multicolumn{2}{|c|}{$80^{\circ} \mathrm{C}$} & 75 \\
\hline 13 & \multicolumn{2}{|c|}{$1(0.60 \mathrm{mmol})$} & 84 \\
\hline 14 & \multicolumn{2}{|c|}{2 (1.5 equiv.) } & 99 \\
\hline
\end{tabular}

${ }^{a}$ Standard conditions: 1 ( 1.2 equiv.), 2 ( $0.30 \mathrm{mmol}, 1.0$ equiv.), $\mathrm{Cu}(\mathrm{OTf})_{2}$ (3 mol\%), DCM $(1.0 \mathrm{~mL}), 25{ }^{\circ} \mathrm{C}, 12 \mathrm{~h} .{ }^{b}$ Isolated yield (average of 2 independent runs). DCE $=1,2$-dichloroethane, DCM $=$ dichloromethane.
Reaction at $50{ }^{\circ} \mathrm{C}$ (entry 11) obtained a comparable yield, while somewhat lower yields were obtained at $0{ }^{\circ} \mathrm{C}$ and $80{ }^{\circ} \mathrm{C}$ (entries 10 and 12). Change of other parameters such as the amount of the substrates were also have an impact on this transformation (entries 13 and 14).

With the optimal reaction conditions in hand, we sought to explore the generality of this thioetherification reaction. Firstly, a wide range of thiophenols bearing electron-poor (3-10) or electron-rich substituents (11-14) on the arene afforded the desired products smoothly (Fig. 1). The electronic properties of alkenyl halides did not show an obvious effect on the efficiency of this transformation. Notably, the 4-Cl substituted thiophenol (4) was shown to participate in the reaction to provide better satisfying result than the 2- or 3-positions (5-6). In addition, polysubstituted thiophenols $(\mathbf{9 - 1 0}, \mathbf{1 4})$ were also proved to be compatible. Excellent coupling results with good chemoselectivity were also observed for the substituents on the thiophenols with active hydrogen, such as containing carboxyl or hydroxyl groups or moieties (15-16). It was found that naphthyl(17) and heteroaromatic-substituted thiophenols such as thiophene (18) were also suitable substrates with good yields. Furthermore, the primary and secondary thioalcohols, as exemplified in 19-24, were effective to couple with 2phenylpropan-2-ol 1, manifesting that the scope of thioalcohols was broad. The compatible functional groups on the primary thioalcohols include terminal alkane, and ester. The secondary thioalcohols derived from alkane (22) afforded the product in good yield. However, a slight decrease in yields were observed when cyclic alkyl thioalcohols include 5-, and 6-membered rings (23-24) were used as the substrates. No reaction took place when tertiary butyl thiol was subjected to the reaction, which is indicative of the dependence of coupling efficiency on the steric encumbrance. Finally, the thioetherification protocol was extendable to the coupling of symmetrical alkyl or aryl dithioalcohol with 2-phenylpropan-2-ol 1, which furnished 25 and 26 in 99\% and 85\% yields, respectively. In this case, two sulfur containing quaternary carbon centers were established simultaneously in an efficient manner.

Our attention was then shifted to the scope of the benzyl alcohol partner. As shown in Fig. 1, primary, secondary and tertiary benzyl alcohols bearing a variety of substituents underwent this thioetherification smoothly with gratifying yields. Signally, this Cu-catalyst system coupled a thioalcohol in the presence of different edition of tertiary benzyl alcohols with moderate to high yields (27-29). Under these exceptionally mild reaction conditions, even a sensitive functional group like the alkynyl group (29) remained intact. It was found that secondary benzyl alcohols (30-36) were also suitable substrates. Notably, benzyl alcohols bearing a variety of electron-rich substituents (32-33) such as $\mathrm{Me}$, and $\mathrm{MeO}$ on the aromatic ring underwent this transformation efficiently with better yields than electrondeficient substituents. 1,2,3,4-Tetrahydronaphthalen-1-ol (35) could also undergo the reaction, providing access to benzocyclohexane derivative in $90 \%$ yield. Moreover, $\alpha$-hydroxy alcohol derived product (36) could be prepared by this method as well in satisfied result. To further expand the usefulness of this tactic, we attached thioalcohol moiety to a variety of primary benzyl 


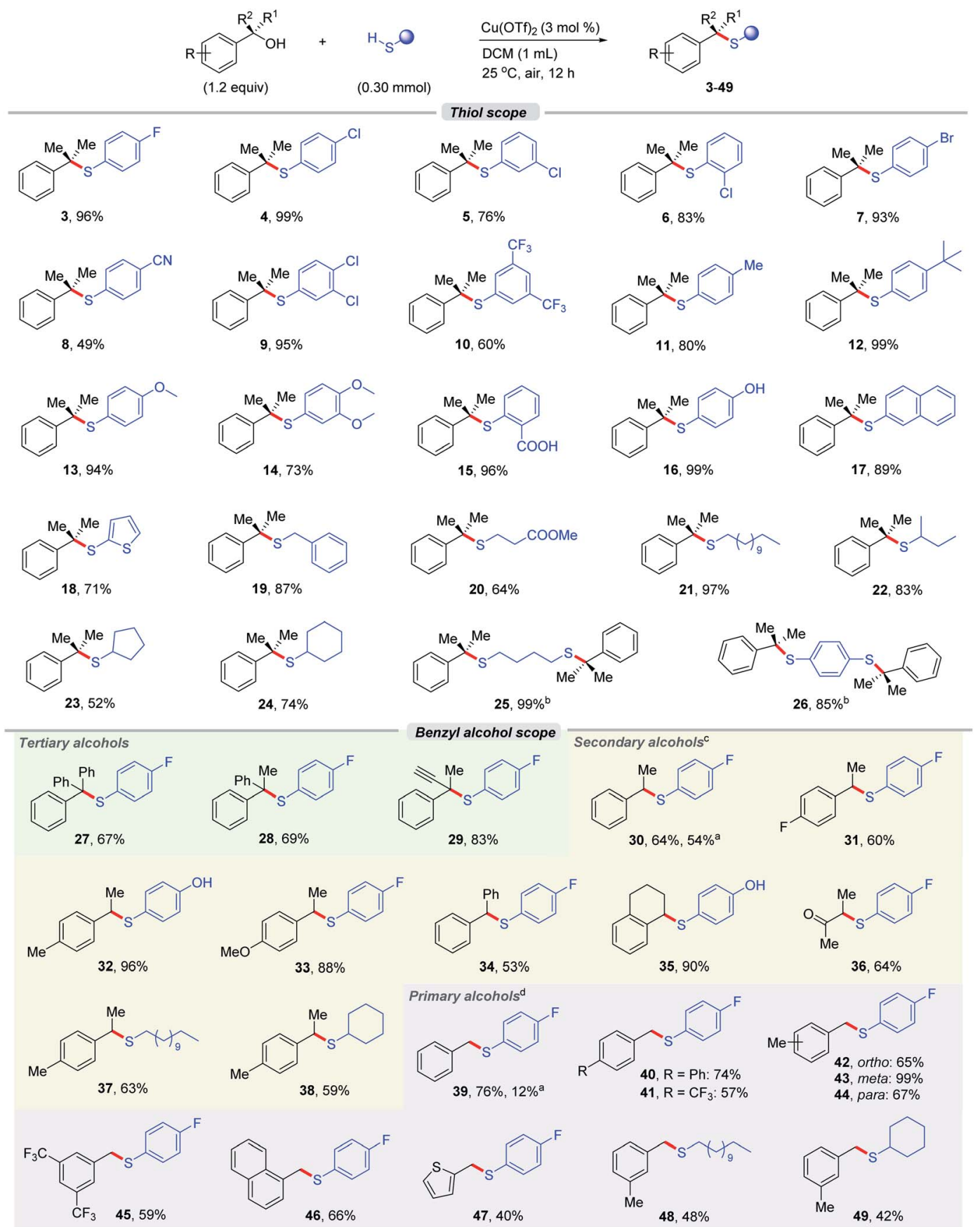

Fig. 1 The scope of thiols and benzyl alcohols. ${ }^{a}$ The standard reaction conditions; isolated yields are provided (average of 2 independent runs). ${ }^{b}$ 2-Phenylpropan-2-ol 1 (2.4 equiv.). ${ }^{c} \mathrm{Cu}(\mathrm{OTf})_{2}$ (8 mol\%), DCE instead of DCM, $40{ }^{\circ} \mathrm{C} .{ }^{d} \mathrm{Cu}(\mathrm{OTf})_{2}(8 \mathrm{~mol} \%), \mathrm{DCE}$ instead of DCM, $80{ }^{\circ} \mathrm{C}$.

alcohols. Remarkably, all of these substrates bearing electronpoor or -rich substituents include $\mathrm{Ph}, \mathrm{CF}_{3}$, and $\mathrm{Me}$ on the arene examined in our hand underwent the transformation in moderate to excellent yields (39-45). Emphatically, the metasubstituted primary benzyl alcohol (43) was shown to participate in the reaction to provide better result than the ortho- or para-positions $(\mathbf{4 2}, \mathbf{4 4})$. Besides, naphthalene (46), and thiophene (47) activated primary alcohols were also competent coupling partners in this reaction system. Moreover, the secondary and primary benzyl alcohols could also reacted with aliphatic thiols (primary and secondary) in moderate yields (3738, 48-49).

After an additional screening of the reaction conditions revealed that the use of $\mathrm{Cu}(\mathrm{OTf})_{2}(8 \mathrm{~mol} \%)$ in DCE at an air atmosphere of $70^{\circ} \mathrm{C}$ that were also applicable for the amination of benzyl alcohols with benzenamine (Fig. 2). Whereas, the amination process was competent with a set of primary, secondary and tertiary benzyl alcohols that delivered the benzyl amines 50-51 in moderate yields, in which a molecular sieve or a base additive was not needed..$^{22,23}$ The stability of carbocation 


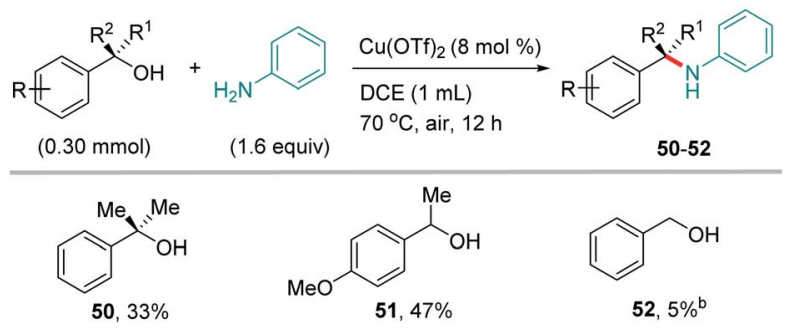

Fig. 2 The amination of benzyl alcohols with benzenamine. ${ }^{a}$ The standard reaction conditions; isolated yields are provided (average of 2 independent runs). ${ }^{b}$ Determined by ${ }^{1} \mathrm{H}$ NMR using 2,5 -dimethylfuran as internal reference.

appeared to affect the amination efficiency. For instance, the amination process was not compatible with primary benzyl alcohol 52.

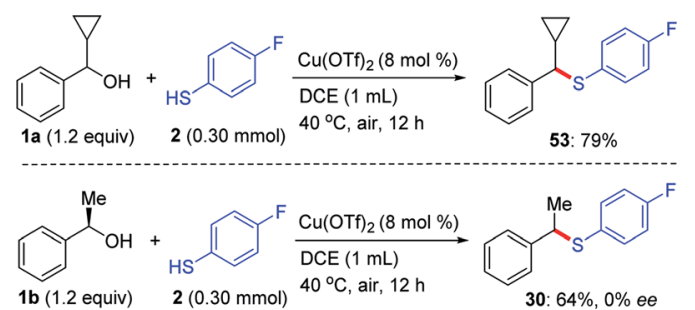

Several mechanism experiments were conducted to get insight into the details on the $\mathrm{C}-\mathrm{S}$ bond transformation reaction. ${ }^{21}$ Firstly, cyclopropyl-containing alcohol 1a was subjected to the reaction conditions to test whether the $\mathrm{C}-\mathrm{O}$ bond cleavage event involves formation of alkyl radicals. The cyclopropane-containing product $\mathbf{5 3}$ was obtained in $\mathbf{7 9 \%}$ yield and didn't accompany by the producing of ring-opening product, which inconsistent with a proposal of the participation of a radical intermediate (eqn (1), top). To further verify the reaction mechanism, the thioetherification of $(R)-1$ phenylethan-1-ol 1b (99\% ee, commercial) with 4-fluorobenzenethiol 2 was carried out under the standard condition, giving the thioether 30 in $64 \%$ yield constituting a $1: 1$ mixture of enantiomers (eqn (1), bottom). The racemization of the alcohol in the thioetherification event supports a mechanistic scenario that proceeds through a carbocation intermediate. These results reveal that the reaction should proceed through a Lewis acid mediated $\mathrm{S}_{\mathrm{N}} 1$-type nucleophilic attack of in situ formed carbocations ${ }^{24}$

\section{Conclusions}

In conclusion, we have developed a Cu-catalyzed coupling of benzyl alcohols with thiols via $\mathrm{C}-\mathrm{O}$ bond cleavage to forge $\mathrm{C}-\mathrm{S}$ bond. A set of thioethers, significant pharmaceutically interested scaffolds, were efficiently synthesized from easily accessible primary, secondary and tertiary benzyl alcohols and thioalcohols/phenols in the presence of $\mathrm{Cu}(\mathrm{OTf})_{2}$ as the Lewis acid catalysis under mild conditions. Significantly, the present method tolerates a variety of functional groups, affording the coupling products generally in modest to excellent yields. The preliminary mechanistic study indicates that the reaction likely to go through the process of carbocation species. Further mechanistic studies are currently in progress in our laboratory.

\section{Author contributions}

B. X. and Y. L. performed experiments and analyzed data. Y. Y. designed research and wrote the paper. L. X. analyzed part of data. T. X. and X.-Y. Y. revised the paper.

\section{Conflicts of interest}

There are no conflicts to declare.

\section{Acknowledgements}

This work was supported by the National Natural Science Foundation of China (82073686, 81730108, and 81973635), Hangzhou Normal University startup fund (2021QDL042, 2019QDL003), the Ministry of Science and Technology of China (High-end foreign experts program, G20200217005 and G2021017004), Hangzhou City "115" plan to introduce overseas intelligence projects (20200215), Hangzhou Normal University School of Medicine Teaching Reform Fund (4125b30100112).

\section{Notes and references}

1 (a) M. Wang and X. Jiang, The Same Oxidation-State Introduction of Hypervalent Sulfur via Transition-Metal Catalysis, Chem. Rec., 2021, 21, 1-19; (b) N. Wang, P. Saidhareddy and X. Jiang, Construction of Sulfurcontaining Moieties In the Total Synthesis of Natural Products, Nat. Prod. Res., 2020, 37, 246-275; (c) M. Wang and X. Jiang, Recent Advances in Sulfuration Chemistry Enabled by Bunte Salts, Aldrichimica Acta, 2020, 53, 19-35.

2 (a) E. A. Ilardi, E. Vitaku and J. T. Njardarson, Data-mining for Sulfur and Fluorine: An Evaluation of Pharmaceuticals to Reveal Opportunities for Drug Design and Discovery, $J$. Med. Chem., 2014, 57, 2832-2842; (b) B. R. Smith, C. M. Eastman and J. T. Njardarson, Beyond C, H, O, and $\mathrm{N}$ ! Analysis of the Elemental Composition of U.S. FDA Approved Drug Architectures, J. Med. Chem., 2014, 57, 9764-9773; (c) H.-Y. Xiong, X. Pannecoucke and T. Besset, Recent Advances in the Synthesis of $\mathrm{SCF}_{2} \mathrm{H}$ - and $\mathrm{SCF}_{2} \mathrm{FG}$ Containing Molecules, Chem.-Eur. J., 2016, 22, 16734-16749.

3 (a) A. Mishra, C. Q. Ma and P. Bäuerle, Functional Oligothiophenes: Molecular Design for Multidimensional Nanoarchitectures and Their Applications, Chem. Rev., 2009, 109, 1141-1276; (b) M. Wang, Q. Fan and X. Jiang, Transition-Metal-Free Diarylannulated Sulfide and Selenide Construction via Radical/Anion-Mediated Sulfur-Iodine and Selenium-Iodine Exchange, Org. Lett., 2016, 18, 57565759.

4 (a) A. D. Borthwick, 2,5-Diketopiperazines: Synthesis, Reactions, Medicinal Chemistry, and Bioactive Natural Products, Chem. Rev., 2012, 112, 3641-3761; (b) 
K. C. Nicolaou, C. R. H. Hale, C. Nilewski and H. A. Ioannidou, Constructing Molecular Complexity and Diversity: Total Synthesis of Natural Products of Biological and Medicinal Importance, Chem. Soc. Rev., 2012, 41, 5185-5238; (c) E. K. Davison and J. Sperry, Natural Products with Heteroatom-Rich Ring Systems, J. Nat. Prod., 2017, 80, 3060-3079; (d) Y. Gao, H. Zhang, F. Lirussi, C. Garrido, X.-Y. Ye and T. Xie, Dual Inhibitors of Histone Deacetylases and Other Cancer-related Targets: A Pharmacological Perspective, Biochem. Pharmacol., 2020, 182, 114224-114252; (e) S. Hu, Z. Hui, F. Lirussi, C. Garrido, X.-Y. Ye and T. Xie, Small Molecule DNA-PK Inhibitors as Potential Cancer Therapy: A Patent Review (2010-present), Expert Opin. Ther. Pat., 2021, 31, 435-452; (f) B. Zhai, N. Zhang, X. Han, Q. Li, M. Zhang, X. Chen, G. Li, R. Zhang, P. Chen, W. Wang, C. Li, Y. Xiang, S. Liu, T. Duan, J. Lou, T. Xie and X. Sui, Molecular Targets of $\beta$ Elemene, a Herbal Extract Used in Traditional Chinese Medicine, and Its Potential Role in Cancer Therapy: A Review, Biomed. Pharmacother., 2019, 114, 108812-108822.

$5 \mathrm{H}$. Liu and X. Jiang, Transfer of Sulfur: From Simple to Diverse, Chem.-Asian J., 2013, 8, 2546-2563.

6 (a) D. P. Nair, M. Podgorski, C. Shunsuke, T. Gong, W. X. Xi, C. R. Fenoli and C. N. Bowman, The Thiol-Michael Addition Click Reaction: A Powerful and Widely Used Tool in Materials Chemistry, Chem. Mater., 2014, 26, 724-744; (b) H. Bürchstümmer, A. Weissenstein, D. Bilalas and F. Würthner, Synthesis and Characterization of Optical and Redox Properties of Bithiophene-Functionalized Diketopyrrolopyrrole Chromophores, J. Org. Chem., 2011, 76, 2426-2432; (c) K. Takimiya, I. Osaka, T. Mori and M. Nakano, Organic Semiconductors Based on [1] Benzothieno[3,2-b][1]benzothiophene Substructure, Acc. Chem. Res., 2014, 47, 1493-1502.

7 (a) C. Dufresne, M. Gallant, Y. Gareau, R. Ruel, L. Trimble and M. Labelle, Synthesis of Montelukast (MK-0476) Metabolic Oxidation Products, J. Org. Chem., 1996, 61, 8518-8525; (b) P. Schmidt, C. Kolb, A. Reiser, M. Philipp, M. Godejohann, H. Helmboldt, H.-C. Müller and K. Karaghiosoff, Formation of a Thiol-Ene Addition Product of Asthma Medication Montelukast Caused by a Widespread Tin-Based Thermal Stabilizer, Chem. Res. Toxicol., 2020, 33, 2963-2971.

8 M. Feng, B. Tang, S. H. Liang and X. Jiang, Sulfur Containing Scaffolds in Drugs: Synthesis and Application in Medicinal Chemistry, Curr. Top. Med. Chem., 2016, 16, 1200-1216.

9 D. Kantoci, E. D. Murray, D. D. Quiggle and W. J. Wechter, Endogenous Natriuretic Factors. 5. Synthesis and Biological Activity of a Natriuretic Metabolite of Diltiazem and Its Derivatives, J. Med. Chem., 1996, 39, 1196-1200.

10 F. J. King, A. D. Searle and M. W. Urquhart, RanitidineInvestigations into the Root Cause for the Presence of $\mathrm{N}$ Nitroso-N,N-dimethylamine in Ranitidine Hydrochloride Drug Substances and Associated Drug Products, Org. Process Res. Dev., 2020, 24, 2915-2926.
11 D. Y. Lin, S.-Z. Zhang, E. Block and L. C. Katz, Encoding Social Signals in the Mouse Main Olfactory Bulb, Nature, 2005, 434, 470-477.

12 (a) B. C. Ranu and R. Jana, Ionic Liquid as Catalyst and Reaction Medium: A Simple, Convenient and Green Procedure for the Synthesis of Thioethers, Thioesters and Dithianes Using An Inexpensive Ionic Liquid, [pmIm]Br, Adv. Synth. Catal., 2005, 347, 1811-1818; (b) Y. Yang, Z. Ye, X. Zhang, Y. Zhou, X. Ma, H. Cao, H. Li, L. Yu and Q. Xu, Efficient Dehydrative Alkylation of Thiols with Alcohols Catalyzed by Alkyl Halides, Org. Biomol. Chem., 2017, 15, 9638-9642; (c) I. Sorribes and A. Corrma, Nanolayered Cobalt-molybdenum Sulphides (Co-Mo-S) Catalyse Borrowing Hydrogen C-S Bond Formation Reactions of Thiols or $\mathrm{H}_{2} \mathrm{~S}$ with Alcohols, Chem. Sci., 2019, 10, 31303142; (d) K. Bahrami, M. M. Khodaei and N. Khodadoustana, TAPC-Catalyzed Synthesis of Thioethers from Thiols and Alcohols, Synlett, 2011, 15, 2206-2210.

13 (a) J. Cornella, C. Zarate and R. Martin, Metal-Catalyzed Activation of Ethers via C-O Bond Cleavage: a New Strategy for Molecular Diversity, Chem. Soc. Rev., 2014, 43, 80818097; (b) B. Su, Z.-C. Cao and Z.-J. Shi, Exploration of Earth-Abundant Transition Metals (Fe, Co, and $\mathrm{Ni}$ ) as Catalysts in Unreactive Chemical Bond Activations, Acc. Chem. Res., 2015, 48, 886-896; (c) S. M. Pound and M. P. Watson, Asymmetric Synthesis via Stereospecific C-N and C-O Bond Activation of Alkyl Amine and Alcohol Derivatives, Chem. Commun., 2018, 54, 12286-12301; (d) B. M. Rosen, K. W. Quasdorf, D. A. Wilson, N. Zhang, A. M. Resmerita, N. K. Garg and V. Percec, NickelCatalyzed Cross-Couplings Involving Carbon-Oxygen Bonds, Chem. Rev., 2011, 111, 1346-1416; (e) E. J. Tollefson, L. E. Hanna and E. R. Jarvo, Stereospecific Nickel-Catalyzed Cross-Coupling Reactions of Benzylic Ethers and Esters, Acc. Chem. Res., 2015, 48, 2344-2353.

14 (a) E. Bisz and M. Szostak, Iron-Catalyzed C-O Bond Activation: Opportunity for Sustainable Catalysis, ChemSusChem, 2017, 10, 3964-3981; (b) B. Sundararaju, M. Achard and C. Bruneau, Transition Metal Catalyzed Nucleophilic Allylic Substitution: Activation of Allylic Alcohols via $\pi$-Allylic Species, Chem. Soc. Rev., 2012, 41, 4467-4483; (c) J. Liu, Y. Ye, J. L. Sessler and H. Gong, Cross-Electrophile Couplings of Activated and Sterically Hindered Halides and Alcohol Derivatives, Acc. Chem. Res., 2020, 53, 1833-1845.

15 (a) M. Tobisu and N. Chatani, Cross-Couplings Using Aryl Ethers via $\mathrm{C}-\mathrm{O}$ Bond Activation Enabled by Nickel Catalysts, Acc. Chem. Res., 2015, 48, 1717-1726; (b) H. Zeng, Z. Qiu, A. Domínguez-Huerta, Z. Hearne, Z. Chen and C.-J. Li, An Adventure in Sustainable Cross-Coupling of Phenols and Derivatives via Carbon-Oxygen Bond Cleavage, ACS Catal., 2017, 7, 510-519; (c) Y. Ye, H. Chen, J. L. Sessler and H. Gong, Zn-Mediated Fragmentation of Tertiary Alkyl Oxalates Enabling Formation of Alkylated and Arylated Quaternary Carbon Centers, J. Am. Chem. Soc., 2019, 141, 820-824; (d) Y. Ye, H. Chen, K. Yao and 
H. Gong, Iron-Catalyzed Reductive Vinylation of Tertiary Alkyl Oxalates with Vinyl Bromides, Org. Lett., 2020, 22, 2070-2075.

16 (a) T. Kondo and T.-A. Mitsudo, Metal-Catalyzed CarbonSulfur Bond Formation, Chem. Rev., 2000, 100, 3205-3220; (b) I. P. Beletskaya and V. P. Anikov, Transition-MetalCatalyzed C-S, C-Se, and C-Te Bond Formation via CrossCoupling and Atom-Economic Addition Reactions, Chem. Rev., 2011, 111, 1596-1636; (c) E. Alvaro and J. F. Hartwig, Resting State and Elementary Steps of the Coupling of Aryl Halides with Thiols Catalyzed by Alkylbisphosphine Complexes of Palladium, J. Am. Chem. Soc., 2009, 131, 7858-7868; (d) M. A. Fernandez-Rodriguez, Q. Shen and J. F. Hartwig, A General and Long-Lived Catalyst for the Palladium-Catalyzed Coupling of Aryl Halides with Thiols, J. Am. Chem. Soc., 2006, 128, 2180-2181; (e) D. Ma, Q. Geng, H. Zhang and Y. Jiang, Assembly of Substituted Phenothiazines by a Sequentially Controlled CuI/L-ProlineCatalyzed Cascade C-S and C-N Bond Formation, Angew. Chem., Int. Ed., 2010, 49, 1291-1294.

17 (a) H. Cao, L. Chen, J. Liu, H. Cai, H. Deng, G. Chen, C. Yan and Y. Chen, Regioselective Copper-catalyzed Thiolation of Imidazo[1,2-a]pyridines: An Efficient C-H Functionalization Strategy for C-S Bond Formation, RSC Adv., 2015, 5, 2235622360; (b) R. Ferraccioli, Heterocycle Synthesis Based on Palladium-Catalyzed C-H Bond Functionalization Methods, Curr. Org. Synth., 2012, 9, 96-113.

18 (a) E. A. Fehnel and M. Carmack, The Ultraviolet Absorption Spectra of Organic Sulfur Compounds. I. Compounds Containing the Sulfide Function, J. Am. Chem. Soc., 1949, 71, 84-93; (b) M. E. Cain, M. B. Evans and D. F. Lee, Reversible Formation and Solvolysis of Tertiary Alkyl Sulphides in Acetic Acid-perchloric Acid, J. Chem. Soc., 1962, 1694-1699; (c) B. P. Bandgar, S. S. Gawande and D. B. Muley, Silica Supported Perchloric Acid $\left(\mathrm{HClO}_{4}-\mathrm{SiO}_{2}\right)$ : a Green, Reusable, and Highly Efficient Heterogeneous Catalyst for theSynthesis of Thioethers Under Solvent-free Conditions at Room Temperature, Green Chem. Lett. Rev., 2020, 3, 49-54.

19 For selected examples for the thiolation of alcohols under Lewis acid and transition metal catalysis, see: (a) S. Biswas and J. S. M. Samec, The Efficiency of the Metal Catalysts in the Nucleophilic Substitution of Alcohols is Dependent on the Nucleophile and Not on the Electrophile, Chem.-Asian J., 2013, 8, 974-981; (b) A. K. Maity, P. N. Chatterjee and S. Roy, Multimetallic $\mathrm{Ir}_{-} \mathrm{Sn}_{3}$-catalyzed Substitution Reaction of $\pi$-activated Alcohols with Carbon and Heteroatom Nucleophiles, Tetrahedron, 2013, 69, 942-956; (c) R. A. Croft, J. J. Mousseau, C. Choi and J. A. Bull, LithiumCatalyzed Thiol Alkylation with Tertiary and Secondary Alcohols: Synthesis of 3-Sulfanyl-Oxetanes as Bioisosteres, Chem.-Eur. J., 2018, 24, 818-821; (d) R. R. Singh, A. Whittington and R. S. Srivastava, Molybdenum (VI)catalyzed Dehydrative Construction of Ce-O and Ce-S Bonds Formation via Etherification and Thioetherification of Alcohols and Thiols, Mol. Catal., 2020, 492, 110954110958; (e) A. Saxena, A. Kumar and S. Mozumdar, Ni- nanoparticles: A Mild Chemo-selective Catalyst for Synthesis of Thioethers, Appl. Catal., A, 2007, 317, 210-215; $(f)$ K. J. Miller and M. M. Abu-Omar, Palladium-Catalyzed $\mathrm{S}_{\mathrm{N}} 1$ Reactions of Secondary Benzylic Alcohols: Etherification, Amination, and Thioetherification, Eur. J. Org. Chem., 2003, 1294-1299; (g) X. Han and J. Wu, $\mathrm{Ga}(\mathrm{OTf})_{3}$-Catalyzed Direct Substitution of Alcohols with Sulfur Nucleophiles, Org. Lett., 2010, 12, 5780-5782.

20 For selected examples of the thiolation of benzyl alcohols under Lewis acid catalysis, see: (a) H. Firouzabadi, $\mathrm{N}$. Iranpoor and $\mathrm{M}$. Jafarpour, $\mathrm{ZrCl}_{4}$ Dispersed on Dry Silica Gel Provides A Useful Reagent for S-alkylation of Thiols With Alcohols Under Solvent-free Conditions, Tetrahedron Lett., 2006, 47, 93-97; (b) A. Singh, S. Gupta and J. M. Khurana, Zinc Chloride Mediated Nucleophilic Substitution: Amination and Thioetherification of Alcohols at Room Temperature, Org. Prep. Proced. Int., 2020, 52, 110-119; (c) Z.-P. Zhang, J.-L. Yu, H.-J. Liu, Y.-Y. Cui, R.-F. Yang, W.-Z. Yang and J.-P. Li, A General and Efficient $\mathrm{FeCl}_{3}$-catalyzed Nucleophilic Substitution of Propargylic Alcohols, J. Org. Chem., 2006, 71, 8298-8301; (d) K. Kuciński and G. Hreczycho, Highly Efficient and Chemoselective Tertiary and Secondary Benzylation of Thiols Catalyzed by Indium(III) Triflate, Eur. J. Org. Chem., 2017, 5572-5581; (e) Y. Guindon, R. Frenette, R. Fortin and J. Rokach, Direct Synthesis of Thioethers from Thiols and Alcohols, J. Org. Chem., 1983, 48, 1357-1359.

21 See the ESI $\dagger$ for details.

22 (a) D. M. Peacock, C. B. Roos and J. F. Hartwig, PalladiumCatalyzed Cross Coupling of Secondary and Tertiary Alkyl Bromides with a Nitrogen Nucleophile, ACS Cent. Sci., 2016, 2, 647-652; (b) X. Zhang, J. Ren, J. M. Tan, D. Tan, R. Lee and C.-H. Tan, An Enantioconvergent Halogenophilic Nucleophilic Substitution $\left(\mathrm{S}_{\mathrm{N}} 2 \mathrm{X}\right)$ Reaction, Science, 2019, 363, 400-404.

23 For elegant examples of the conversion of the tertiary $\mathrm{Csp}^{3}-\mathrm{O}$ bond to $\mathrm{Csp}^{3}-\mathrm{N}$ bonds, see: (a) P. T. Marcyk, L. R. Jefferies, D. I. AbuSalim, M. Pink, M.-H. Baik and S. P. Cook, Stereoinversion of Unactivated Alcohols by Tethered Sulfonamides, Angew. Chem., Int. Ed., 2019, 58, 1727-1731; (b) S. V. Pronin, C. A. Reiher and R. A. Shenvi, Stereoinversion of Tertiary Alcohols to Tertiary-alkyl Isonitriles and Amines, Nature, 2013, 501, 195-199; (c) Intra-amination of benzylic alcohol: R. A. Watile, A. Bunrit, J. Margalef, S. Akkarasamiyo, R. Ayub, E. Lagerspets, S. Biswas, T. Repo and J. S. M. Samec, Intramolecular Substitutions of Secondary and Tertiary Alcohols with Chirality Transfer by An Iron(III) Catalyst, Nat. Commun., 2019, 10, 3826-3834; (d) For a review, see: V. Lanke and I. Marek, Stereospecific Nucleophilic Substitution at Tertiary and Quaternary Stereocentres, Chem. Sci., 2020, 11, 9378-9385.

24 Y. Gong, Z. Zhu, Q. Qian, W. Tong and H. Gong, Zn- and CuCatalyzed Coupling of Tertiary Alkyl Bromides and Oxalates to Forge Challenging C-O, C-S, and C-N Bonds, Org. Lett., 2021, 23, 1005-1010. 